\title{
Práticas Pedagógicas Publicadas na Revista Brasileira de Educação do Campo: Articulação do Ensino de Ciências e da Educação do Campo
}

\author{
Pedagogical Practices Published in the Brazilian Journal of Rural \\ Education: Articulation of Science Education and Rural Education
}

Graciele dos Santos dos Santos (graciele.rayana@gmail.com) Universidade Federal do Pampa - UNIPAMPA, Campus Dom Pedrito

Ana Carolina de Oliveira Salgueiro de Moura (anamoura@unipampa.edu.br)

Universidade Federal do Pampa - UNIPAMPA, Campus Dom Pedrito

Resumo: Que estratégias de ensino tomam por base as peculiaridades do campo, seus sujeitos e culturas? Quais potencializam a articulação do Ensino de Ciências com a Educação do Campo? A investigação apresentada nesse artigo objetiva identificar práticas pedagógicas que articulam a Educação do Campo com o Ensino de Ciências de maneira contextualizada, mobilizam conhecimentos prévios, contextualizam o conhecimento científico e possibilitam o aprender em ação. Com abordagem qualitativa e pesquisa bibliográfica, foi realizado levantamento, sistematização e análise de publicações da Revista Brasileira de Educação do Campo, (v.1, n.1, 2016 - v.4, n.1, 2019), acerca de diferentes estratégias de ensino que articulam e integram a Educação do Campo e o Ensino de Ciências. Os resultados mostram que essa articulação é possível por meio de práticas pedagógicas que envolvem: temas geradores; fenômenos como mediadores dos conhecimentos; softwares educacionais; modelagem matemática; júri simulado; Ciência, Tecnologia e Sociedade (CTS); jogos matemáticos; abordagem intercultural; Ciência, Tecnologia, Sociedade e Ambiente (CTSA); e tempestade cerebral. As bases dessa diversidade de práticas são: ação do estudante no processo de aprender; relação entre saberes populares e conhecimento científico; e valorização dos conhecimentos prévios e do contexto local, podendo ser adaptadas de acordo com a disciplina e o nível de ensino.

Palavras-chave: Práticas Pedagógicas; Educação do Campo; Ensino de Ciências.

Abstract: What teaching strategies are based on the peculiarities of the field, its subjects and cultures? Which enhance the articulation of Science Teaching with Rural Education? The research presented in this article aims to identify pedagogical practices that link Rural Education with Science Teaching in a contextualized way, mobilize previous knowledge, contextualize scientific knowledge and enable learning in action. With a qualitative approach and bibliographic research, a survey, systematization and analysis of publications of the Revista Brasileira de Educação do Campo, (v.1, n.1, 2016 - v.4, n.1, 2019) was carried out, about different strategies of teaching that articulate and integrate Rural Education and Science Teaching. The results show that this articulation is possible through pedagogical practices that involve: generating themes; phenomena as mediators of knowledge; educational software; mathematical modeling; simulated jury; Science, Technology and Society (CTS); mathematical 
games; intercultural approach; Science, Technology, Society and Environment (CTSA); and brain storm. The bases of this diversity of practices are: student action in the learning process; relationship between popular knowledge and scientific knowledge; and valuing previous knowledge and the local context, which can be adapted according to the discipline and level of education.

Keywords: Pedagogical Practices; Rural Education; Science teaching.

\section{INQUIETAÇÕES QUE DERAM ORIGEM A PESQUISA}

A investigação apresentada nesse artigo traz como ponto de partida algumas inquietações, produzidas a partir das experiências em estágio ${ }^{1}$ vivenciadas em escolas do campo e no processo de formação da primeira autora, no curso de Educação do Campo - Licenciatura, desenvolvido na Universidade Federal do Pampa, Campus Dom Pedrito; bem como a partir das reflexões possibilitadas por essas experiências.

A formação de professores por meio de Licenciaturas em Educação do Campo teve início em 2007 como política pública do Ministério da Educação (MOLINA, 2015), ou seja, é um processo recente de formação "para" e "com" as especificidades do campo. Assim, além dos desafios inerentes a formação de professores, associa-se aos mesmos as peculiaridades e demandas do campo. No caso da Licenciatura em questão, associam-se a esses desafios a integração da Educação do Campo com o Ensino de Ciências, área de formação do curso.

Por meio das experiências nos estágios ficou evidente a compreensão da sala de aula como um espaço de diversidade, mesmo em turmas regulares os estudantes são diferentes: diferentes histórias, diferentes estilos de aprendizagem e diferentes dificuldades de aprendizagem. Essa diversidade é mais claramente experienciada nas classes multisseriadas, organização comum em escolas do campo. A proposição dessa pesquisa parte dessa compreensão, de que a sala de aula é um espaço de diversidade, um espaço heterogêneo no que se refere as maneiras de aprender e as dificuldades de aprendizagem. No espaço escolar há vários casos de estudantes que apresentam diferenças no desenvolvimento cognitivo: seja em função da diversidade própria da sala de aula, seja por dificuldades de aprendizagem ou pela organização em classes

\footnotetext{
${ }^{1}$ As experiências de estágio possibilitaram a vivência de desafios concretos das práticas pedagógicas em escolas do campo, da diversidade de estudantes, da multisseriação e das dificuldades de aprendizagem de alguns estudantes.
} 
multisseriadas, contextos que evidenciam a importância da abordagem desse trabalho e que também justificam o mesmo. Assim, nos questionamos: ao considerarmos as diferenças entre os estudantes, como desenvolver práticas pedagógicas que contemplem essa diversidade? Que estratégias de ensino podem contribuir com o aprender de diferentes estudantes? Que estratégias ou metodologias de ensino colaboram para superação das dificuldades de aprendizagem? Dentre essas estratégias de ensino quais potencializam a articulação do Ensino de Ciências com a Educação do Campo? Que estratégias e metodologias tomam por base as peculiaridades do campo, de seus sujeitos e suas culturas?

Nesse sentido, o problema de pesquisa que orienta o desenvolvimento dessa investigação é expresso pelo seguinte questionamento: “quais práticas pedagógicas possibilitam a articulação da Educação do Campo com o Ensino de Ciências e mobilizam conhecimentos prévios, contextualizam o conhecimento científico e possibilitam o aprender em ação"?. Tal questionamento orienta nosso objetivo principal e se desdobra nos seguintes objetivos específicos: investigar a produção científica publicada na Revista Brasileira de Educação do Campo que contempla práticas pedagógicas vinculadas ao Ensino de Ciências; sistematizar e caracterizar as práticas pedagógicas que tem sido desenvolvidas de maneira a articular a Educação do Campo e o Ensino de Ciências; e contribuir para o fortalecimento da Educação do Campo enquanto espaço de produção de saberes e práticas pedagógicas.

\section{DIVERSIDADE DE ESTUdANTES E PLURALIDADE DE PRÁTICAS PEDAGÓGICAS}

Nessa seção do artigo buscamos explicitar as articulações que fomos construindo a partir de nossas inquietações, as quais justificam nosso interesse em buscar práticas pedagógicas que articulam Educação do Campo com o Ensino de Ciências de maneira contextualizada, mobilizam conhecimentos prévios, e possibilitam o aprender em ação.

Assim, dialogaremos com alguns autores sobre a diversidade na sala de aula, o Ensino de Ciências e a pluralidade metodológica; e o aprender em ação. Considerar as diversidades e diferenças na sala de aula nos faz considerar que, de alguma forma, enquanto professores, trabalhamos na perspectiva da inclusão. 


\begin{abstract}
A condição pedagógica preconiza a inclusão e o acolhimento de todos os alunos, independentemente de suas especificidades físicas, intelectuais, sociais afetivas. Afinal, somos todos únicos, portanto, sempre diferentes entre nós. Como nascemos todos inacabados estamos continuamente caminhando em movimentos de vida e formação, em permanente processo de incorporação de novos acolhimentos e de novas inclusões (FRANCO, 2017, p.965).
\end{abstract}

Ao compreendermos essa perspectiva de inclusão, associamos a mesma a diversidade apresentada nas classes multisseriadas das escolas do campo (espaço de atuação dos Licenciados do curso). É comum a multisseriação em escolas do campo, com isso temos na mesma sala estudantes de diferentes anos, com um único professor. Na maioria das vezes não são dadas ao profissional de educação, orientações de como atuar numa organização multisseriada o que acaba interferindo na aprendizagem.

Associado ao contexto de diversidade da sala de aula e das classes multisseriadas, ainda é preciso levar em conta as especificidades da Educação do Campo, a qual "faz o diálogo com a teoria pedagógica desde a realidade particular dos camponeses, mas preocupada com a educação do conjunto da população trabalhadora do campo e, mais amplamente, com a formação humana" (CALDART, 2004, p.12). Assim, quando falamos em contextualização do conhecimento estamos nos referindo aos processos de "trazer para a sala de aula" as experiências, culturas, ecossistemas e práticas produtivas desses sujeitos do campo. Considerando tais especificidades, se pensarmos também em como efetivar processos formativos na Educação do Campo em articulação com o Ensino de Ciências, ampliamos a complexidade desse fazer educativo.

Ao incluirmos nessa discussão o Ensino de Ciências, trazemos para o diálogo Laburu, Arruda e Nardi (2003, p. 248) que abordam a importância do pluralismo metodológico no Ensino de Ciências, tanto porque as estratégias de ensino que privilegiam “[...] a audição em detrimento da fala, são insuficientes em assegurar que os aprendizes realmente aprendam os conceitos científicos" como também pela diversidade de estilos de aprendizagem dos estudantes em sala de aula. Becker (2008, p.46) contribui para crítica ao ensino diretivo quando coloca que:

[...] quem representa este mundo, na sala de aula, é, por excelência, o professor. Em seu imaginário, ele, e somente ele, pode produzir algum novo conhecimento no aluno. O aluno aprende se, e somente se, o professor ensinar. $\mathrm{O}$ professor acredita no mito da transferência do conhecimento: o que ele sabe não importa o nível de abstração ou de formalização, pode ser transferido ou transmitido para o aluno. Tudo o que o aluno tem a fazer é 
submeter-se à fala do professor: ficar quieto e repetir tantas vezes quantas forem necessárias, escrevendo, lendo, etc., até aderir em sua mente, o que o professor deu.

Processos de ensino como esse tem foco na reprodução, e o estudante tem que se submeter ao silêncio, cumprir regras e não reivindicar coisa alguma. Vasconcelos, Praia e Almeida (2003, p. 14) discutem sobre o Ensino de Ciências por meio da aprendizagem ativa, a qual requer "[...] explorações e descobertas efetivas para o alcance de uma verdadeira compreensão". Esse aprender em ação demanda a mobilização cognitiva dos sujeitos envolvidos na aprendizagem, requer a identificação dos conhecimentos prévios e a contextualização do conhecimento, exige interação e integração professor-estudante e estudante-estudante. O diálogo apresentado nessa seção fortalece nosso argumento para buscarmos por práticas pedagógicas no sentido de diversidade de metodologias, estratégias e recursos didático-pedagógicos possíveis de serem experimentados.

\section{METODOLOGIA}

Esta pesquisa, que traz em seus objetivos os verbos: investigar, compreender, contribuir e sistematizar, foi desenvolvido por meio de pesquisa qualitativa, a qual:

é composta por um conjunto de substantivos cujos sentidos se complementam: experiência, vivência, senso comum e ação. E o movimento que informa qualquer abordagem ou análise se baseia em três verbos: compreender, interpretar e dialetizar (MINAYO, 2012, p. 622).

Com abordagem qualitativa essa pesquisa também se caracteriza como bibliográfica, com levantamento, sistematização e análise de materiais publicados acerca de diferentes estratégias e metodologias de ensino que integram a Educação do Campo e o Ensino de Ciências. De acordo com (LIMA e MIOTO, 2007, p. 38) a pesquisa bibliográfica implica em um conjunto ordenado de procedimentos de buscas por soluções, atento ao objeto de estudo, e que, por isso, não pode ser aleatório. Entendemos que as práticas pedagógicas devem ser compartilhadas para que sejam conhecidas e multiplicadas. Há diferentes espaços de compartilhamento, desde a escola - sala de professores e rodas de formação, como também em eventos científicos, formativos e ainda em periódicos. Optamos por partir das publicações em periódico, pois para Lima e Mioto (2007) a pesquisa bibliográfica possibilita sistematizar investigações dispersas em várias publicações. 
Para realizar a pesquisa bibliográfica escolhemos a Revista Brasileira de Educação do Campo - RBEC $^{2}$, que contempla publicações vinculadas à Educação do Campo sob diferentes campos da pesquisa e tem como objetivo a comunicação científica e a produção de conhecimento na área. Esse periódico está classificado com o Qualis B1 na área de Ensino. A partir da escolha do periódico, realizamos os seguintes procedimentos indicados por Lima e Mioto (2007) como sequência indicada para a pesquisa bibliográfica: a) Seleção de artigos científicos publicados na Revista Brasileira de Educação do Campo que contemplem práticas pedagógicas vinculadas ao Ensino de Ciências; b) Sistematização dos artigos científicos publicados em relação: ao ano de publicação, palavras-chave, nível de ensino, local e prática pedagógica desenvolvida; c) Caracterização das práticas pedagógicas: qual a prática pedagógica, como a mesma foi desenvolvida e quais suas contribuições para o aprender em ação; d) Síntese integradora: "que apresenta a reflexão, realizada a partir do referencial teórico e dos dados obtidos no intuito de realizar uma aproximação crítica dos objetivos propostos" (LIMA e MIOTO, 2007, p. 42).

Como a Revista já versa sobre a Educação do Campo a pesquisa bibliográfica teve como primeiro parâmetro de busca a expressão "Ensino de Ciências", assim contemplamos a articulação dessas duas áreas que definimos nessa investigação. Com essa definição foram encontrados 51 artigos publicados, desde o primeiro volume da revista: volume 1, número 1 de 2016 até o volume 4, número 1 de 2019 , de um total de 10 números e 137 artigos publicados.

Como o dispositivo de busca do periódico só permite a busca de uma expressão por vez, refizemos a busca a partir do termo "metodologia de ensino", a qual resultou em 19 artigos, desses, 4 artigos já haviam aparecido na pesquisa com o termo "Ensino de Ciências" e os outros 15 mesmo tendo aparecido não se tratavam da discussão acerca de alguma metodologia de ensino, apenas faziam menção a uma. Buscamos ainda pelo termo "estratégia de ensino" o qual resultou em 5 artigos, dos quais 4 já haviam aparecido na pesquisa com o termo "Ensino de Ciências" e o outro apenas mencionava uma estratégia de ensino, sem fazer discussões e reflexões sobre a mesma.

\footnotetext{
${ }^{2}$ As experiências de estágio possibilitaram a vivência de desafios concretos das práticas pedagógicas em escolas do campo, da diversidade de estudantes, da multisseriação e das dificuldades de aprendizagem de alguns estudantes.
} 
Para identificar a abordagens dos artigos, tanto aqueles que apareceram como resultado da busca pelo termo "Ensino de Ciências" quanto àqueles que resultaram das buscas por "metodologias de ensino" e "estratégias de ensino", lemos seus resumos e palavras-chaves para selecionar artigos que tratavam do foco da pesquisa: a discussão e reflexão sobre as possibilidades de determinadas metodologias e/ou estratégias de ensino para o Ensino de Ciências. Conforme Lima e Mioto (2007, p. 41):

No caso da pesquisa bibliográfica, a leitura apresenta-se como a principal técnica, pois é através dela que se pode identificar as informações e os dados contidos no material selecionado, bem como verificar as relações existentes entre eles de modo a analisar a sua consistência.

Essa etapa da pesquisa constitui-se de leituras seletivas, reflexivas e interpretativas (LIMA e MIOTO, 2007). Através dessas três leituras conseguimos dar andamento a pesquisa, selecionando o material que de fato nos interessava; de forma ordenada buscando responder aos objetivos da pesquisa. Para contribuir com essa seleção, tomamos como conceito de prática pedagógica a definição dada por Franco (2015, p. 605, 606, 607):

As práticas pedagógicas organizam-se em torno de intencionalidades previamente estabelecidas e tais intencionalidades serão perseguidas ao longo do processo didático, de formas e meios variados. [...] As práticas pedagógicas caminham por entre resistências e desistências, em uma perspectiva dialética, pulsional, totalizante. [...] As práticas pedagógicas trabalham com e na historicidade; implicam tomadas de decisões; de posições e se transformam pelas contradições.

Assim, a seleção de artigos consistiu em definir para pesquisa apenas os artigos que relatavam e construíam reflexões de uma prática pedagógica efetivada (seja estratégia de ensino ou metodologia de ensino). Ou seja, aqueles artigos que apenas mencionavam metodologias ou estratégias de ensino foram excluídos da pesquisa. Com essa seleção e refinamento das buscas identificamos dez artigos; quando encontramos nas obras pesquisadas respostas aos nossos questionamentos e objetivos.

\section{PRÁticas PEdagógicas QUe articulam EdUCAÇÃo do CAMPO E ENSINO DE CIÊNCIAS}

Como primeira parte da sistematização da pesquisa, apresentamos na página seguinte o quadro com os artigos selecionados na Revista Brasileira de Educação do 
Campo, identificando título da publicação, autores, ano, nível de ensino no qual a prática foi efetivada, disciplina, prática pedagógica desenvolvida e tema abordado na mesma.

Organizamos o quadro de maneira a classificar os artigos por nível de ensino, disciplina e prática desenvolvida, procurando aproximar esses itens de classificação. Essa organização foi também utilizada para apresentar as práticas pedagógicas identificadas. Assim, compartilhamos a seguir as práticas pedagógicas publicadas na Revista Brasileira de Educação do Campo (v.1, n.1 de 2016 à v.4, n.1 de 2019) que articulam a Educação do Campo e o Ensino de Ciências, bem como suas contribuições para participação e aprendizagem dos estudantes.

Quadro 1 - Artigos referentes às práticas pedagógicas pesquisadas. Fonte: as autoras.

\begin{tabular}{|c|c|c|c|c|c|c|}
\hline TÍTULO & AUTORES & ANO & $\begin{array}{l}\text { NÍVEL DE } \\
\text { ENSINO }\end{array}$ & DISCIPLINA & $\begin{array}{c}\text { PRÁTICA } \\
\text { PEDAGÓGICA }\end{array}$ & TEMA \\
\hline $\begin{array}{c}\text { Uso de objetos } \\
\text { educacionais digitais } \\
\text { para ensinar } \\
\text { sistemas do corpo } \\
\text { humano em uma } \\
\text { escola do campo }\end{array}$ & $\begin{array}{c}\text { Silvio } \\
\text { Ferreira dos } \\
\text { Santos, } \\
\text { Marcelo } \\
\text { Franco Leão }\end{array}$ & 2017 & $\begin{array}{c}\text { Ensino } \\
\text { fundamental }\end{array}$ & ciências & $\begin{array}{c}\text { Softwares } \\
\text { educacionais e } \\
\text { aplicativos em } \\
\text { dispositivos } \\
\text { móveis }\end{array}$ & $\begin{array}{c}\text { Sistema } \\
\text { digestório e } \\
\text { sistema } \\
\text { circulatório }\end{array}$ \\
\hline $\begin{array}{l}\text { Escola do campo e a } \\
\text { prática social de } \\
\text { ensino da } \\
\text { matemática na } \\
\text { concepção da } \\
\text { comunidade escolar }\end{array}$ & $\begin{array}{c}\text { Ana Paula } \\
\text { Nahirne, } \\
\text { Maria } \\
\text { Strieder }\end{array}$ & $\begin{array}{l}2018 \\
0\end{array}$ & $\begin{array}{c}\text { Ensino } \\
\text { Fundamental } \\
\text { e Médio }\end{array}$ & matemática & $\begin{array}{l}\text { Modelagem } \\
\text { matemática }\end{array}$ & $\begin{array}{l}\text { Medidas } \\
\text { Agrárias, } \\
\text { Produção } \\
\text { Leiteira, } \\
\text { Agricultura } \\
\text { Sustentável }\end{array}$ \\
\hline $\begin{array}{c}\text { Formação de } \\
\text { professores } \\
\text { quilombolas e o } \\
\text { Programa } \\
\text { Etnomatemática: } \\
\text { repensando } \\
\text { processos de ensino } \\
\text { da Matemática }\end{array}$ & $\begin{array}{l}\text { Érika Lúcia } \\
\text { Ferreira de } \\
\text { Jesus, } \\
\text { Roberto } \\
\text { Barcelos } \\
\text { Souza }\end{array}$ & 2018 & $\begin{array}{c}\text { Formação } \\
\text { continuada } \\
\text { de } \\
\text { professores }\end{array}$ & matemática & $\begin{array}{c}\text { Jogos } \\
\text { matemáticos }\end{array}$ & $\begin{array}{l}\text { Cultura } \\
\text { africana }\end{array}$ \\
\hline $\begin{array}{l}\text { Fenômenos como } \\
\text { mediadores do } \\
\text { processo educativo } \\
\text { em Ciências da } \\
\text { Natureza e } \\
\text { Matemática na } \\
\text { Educação do Campo }\end{array}$ & $\begin{array}{c}\text { Marcelo } \\
\text { Gules } \\
\text { Borges, } \\
\text { Juliano } \\
\text { Espezim } \\
\text { Soares } \\
\text { Faria, } \\
\text { Elizandro } \\
\text { Maurício } \\
\text { Brick }\end{array}$ & 2017 & Superior & $\begin{array}{l}\text { ciências e } \\
\text { matemática }\end{array}$ & $\begin{array}{c}\text { Fenômenos como } \\
\text { mediadores dos } \\
\text { conhecimentos }\end{array}$ & $\begin{array}{c}\text { Geadas, } \\
\text { Substituição } \\
\text { da Mata } \\
\text { Nativa por } \\
\text { Pinus e } \\
\text { Reconstituiç } \\
\text { ão da Mata } \\
\text { Ciliar }\end{array}$ \\
\hline $\begin{array}{c}\text { Oficina de tinta de } \\
\text { terra: }\end{array}$ & $\begin{array}{l}\text { Meubles } \\
\text { Borges }\end{array}$ & 2018 & Superior & $\begin{array}{l}\text { história da } \\
\text { química }\end{array}$ & $\begin{array}{c}\text { Ciência, } \\
\text { Tecnologia, }\end{array}$ & $\begin{array}{c}\text { Tinta } \\
\text { produzida a }\end{array}$ \\
\hline
\end{tabular}


Dossiê Educação do Campo e suas Interfaces com o Ensino de Ciências

Vol. 3, n. 4, 2020_Edição Especial

ISSN: 2595- 4520

\begin{tabular}{|c|c|c|c|c|c|c|}
\hline $\begin{array}{l}\text { contextualizando } \\
\text { pigmentos na } \\
\text { disciplina de } \\
\text { História da Química } \\
\text { na LEdoC/UFMA }\end{array}$ & $\begin{array}{l}\text { Junior, } \\
\text { Matheus } \\
\text { Casimiro } \\
\text { Soares } \\
\text { Ferreira, } \\
\text { Carolina } \\
\text { Pereira } \\
\text { Aranha }\end{array}$ & & & & $\begin{array}{l}\text { Sociedade e } \\
\text { Ambiente } \\
\text { (CTSA) }\end{array}$ & $\begin{array}{l}\text { partir da } \\
\text { terra }\end{array}$ \\
\hline $\begin{array}{c}\text { Discutindo a } \\
\text { temática } \\
\text { agrotóxicos: uma } \\
\text { abordagem por meio } \\
\text { das controvérsias } \\
\text { sociocientíficas }\end{array}$ & $\begin{array}{c}\text { Eril } \\
\text { Medeiros da } \\
\text { Fonseca, } \\
\text { Leandro } \\
\text { Duso, } \\
\text { Marilisa } \\
\text { Bialvo } \\
\text { Hoffmann }\end{array}$ & 2017 & Superior & biologia & $\begin{array}{c}\text { Ciência, } \\
\text { Tecnologia e } \\
\text { Sociedade (CTS) }\end{array}$ & Agrotóxicos \\
\hline TÍTULO & AUTORES & ANO & $\begin{array}{c}\text { NÍVEL DE } \\
\text { ENSINO }\end{array}$ & DISCIPLINA & $\begin{array}{c}\text { PRÁTICA } \\
\text { PEDAGÓGICA }\end{array}$ & TEMA \\
\hline $\begin{array}{l}\text { O educar-se no } \\
\text { campo: caneta, } \\
\text { enxada e botânica } \\
\text { camponesa }\end{array}$ & $\begin{array}{c}\text { Matias } \\
\text { Köhler, } \\
\text { Estela } \\
\text { Santos, } \\
\text { Cristiane } \\
\text { Giaretta, } \\
\text { Gilmar } \\
\text { Gomes, } \\
\text { Sebastião } \\
\text { Pinheiro }\end{array}$ & 2018 & Superior & agroecologia & $\begin{array}{l}\text { teórico- } \\
\text { expositiva, } \\
\text { teórico-prática e } \\
\text { reflexiva- } \\
\text { avaliativa }\end{array}$ & $\begin{array}{l}\text { Horta e } \\
\text { plantio }\end{array}$ \\
\hline $\begin{array}{l}\text { O Ensino da Física } \\
\text { na Educação do } \\
\text { Campo: } \\
\text { descolonizadora, } \\
\text { instrumentalizadora } \\
\text { e participativa }\end{array}$ & $\begin{array}{c}\text { Roberto } \\
\text { Gonçalves } \\
\text { Barbosa }\end{array}$ & 2018 & Superior & física & Temas geradores & $\begin{array}{c}\text { Falta de } \\
\text { água ou de } \\
\text { energia } \\
\text { elétrica, } \\
\text { velocidade } \\
\text { de } \\
\text { embarcação, } \\
\text { pressão do ar } \\
\text { em terrário }\end{array}$ \\
\hline $\begin{array}{c}\text { Júri simulado e } \\
\text { tempestade cerebral: } \\
\text { entendendo a } \\
\text { implantação da } \\
\text { Usina Hidrelétrica } \\
\text { de Belo Monte }\end{array}$ & $\begin{array}{c}\text { Marcos } \\
\text { Marques } \\
\text { Formigosa, } \\
\text { Miriam Ines } \\
\text { Marchi, } \\
\text { José } \\
\text { Claudio Del } \\
\text { Pino, Marli } \\
\text { Teresinha } \\
\text { Quartieri }\end{array}$ & 2017 & Superior & física & $\begin{array}{l}\text { Juri simulado e } \\
\text { Tempestade } \\
\text { cerebral }\end{array}$ & $\begin{array}{l}\text { Hidrelétrica } \\
\text { e geração de } \\
\text { energia }\end{array}$ \\
\hline $\begin{array}{l}\text { Interculturalidade e } \\
\text { conhecimento } \\
\text { tradicional sobre a } \\
\text { Lua na formação de } \\
\text { professores no/do } \\
\text { campo }\end{array}$ & $\begin{array}{c}\text { Rodrigo dos } \\
\text { Santos } \\
\text { Crepalde, } \\
\text { Verônica } \\
\text { Klepka, } \\
\text { Tânia } \\
\text { Halley } \\
\text { Oliveira }\end{array}$ & 2017 & Superior & física & $\begin{array}{l}\text { Abordagem } \\
\text { intercultural }\end{array}$ & $\begin{array}{l}\text { Lua e } \\
\text { relações com } \\
\text { plantio e } \\
\text { pesca }\end{array}$ \\
\hline
\end{tabular}


Santos e Leão (2017) trabalharam com softwares e aplicativos em dispositivos móveis com estudantes do $8^{\circ}$ ano do Ensino Fundamental da Escola Estadual Sol Nascente do Mato Grosso na disciplina de ciências. O uso desses recursos tecnológicos digitais teve por objetivo ensinar o sistema digestório e sistema circulatório através dos recursos didáticos "Atlas do corpo humano", "Sistema do corpo humano 3D" e "Jogo da mente". Foram utilizados questionários para avaliar as atividades que ocorreram dois momentos, no primeiro momento se utilizou o livro didático na compreensão dos conceitos sobre os sistemas digestório e circulatório. Em um segundo momento foram utilizados os recursos digitais na compreensão dos sistemas citados acima. Para Santos e Leão (2017, p. 872, p. 868) “o uso de tais ferramentas pedagógicas é cada vez mais necessário no processo educativo" e "[...] tem como propósito promover aprendizagens quanto aos conceitos estudados". A avaliação das atividades mostrou que os estudantes compreenderam melhor os conceitos através dos objetos educacionais digitais. pois os recursos disponibilizam imagens em três dimensões e sinalizam cada parte do corpo humano, oferecendo informações e curiosidades sobre o assunto.

Nahirne e Strieder (2018) desenvolveram suas ações na Escola Estadual do Campo de Rio da Prata - Ensino Fundamental e Médio, de Nova Laranjeira do Paraná, para ver como a matemática está articulada com a Educação do Campo e a partir dos apontamentos de estudantes, equipe diretiva, coordenação pedagógica e professores de Ciências da Natureza e Matemática, eles propõem que essa articulação possa acontecer a partir da modelagem matemática. A modelagem matemática é uma forma de trabalhar um conteúdo em diferentes situações, proporcionando ao educando agir com mais autonomia em seus raciocínios e estimular sua criatividade. Alguns exemplos de abordagem que podem ser feitas com temas a partir da modelagem matemática: "o trabalho com Medidas Agrárias, Produção Leiteira, Aquisição de alimentos, Agricultura Sustentável, entre outros" (NAHIRNE e STRIEDER, 2018, p. 502).

Ferreira de Jesus e Souza (2018) trabalharam com oficinas de jogos de Matemática com docentes, no Programa de Formação de Docentes nas Escolas Quilombolas da Secretaria de Estado de Educação, Cultura e Esporte (SEDUCE) de Goiás. A oficina foi fundada na perspectiva do Projeto Etnomatemática e em jogos de 
origem Africana como: Tsoro Yematatu, Shisima e Oware. Na etnomatemática há diversas formas de explicar ou conviver com contextos naturais e socioculturais, também, políticos e econômicos. O desenvolvimento da oficina ocorreu com a apresentação em slides, onde se passou os seguintes itens: introdução, conceito matemática, conhecimento e cultura. Foram apresentados dentro da educação matemática algumas formas de como se trabalhar em sala de aula de modo a quebrar com o paradigma da matemática universalizada. Realizou-se uma atividade ligada a apropriação da história da matemática, a fim de compreender como, onde e por que surgiu seu conhecimento e sua importância social. Os jogos quando postos aos estudantes, permitem os mesmos jogarem em duplas ou trios, fazendo com que possam estimular suas habilidades e criatividade, sem deixar de valorizar sua cultura.

Borges, Faria e Brick (2017) analisaram a prática pedagógica desenvolvida no curso de Licenciatura em Educação do Campo da Universidade Federal de Santa Catarina no componente curricular denominado "Fundamentos das Ciências da Natureza e Matemática na Educação do Campo 1l”, ministrado por professores das áreas de ensino de matemática, biologia e física. $\mathrm{O}$ objetivo foi estudar fenômenos significativos do ponto de vista social para a população dos lugares aos quais os estudantes pertenciam. Para os autores, os fenômenos são contextos concretos a partir dos quais se pode fazer a compreensão de conceitos científicos abstratos. A prática pedagógica desenvolvida foi realizada a partir de quatro objetivos/ações:

1) definir em conjunto com os estudantes fenômenos com ocorrência e relevância nos seus respectivos territórios; 2) delimitar a dimensão natural dos fenômenos escolhidos; 3 ) estudar os conceitos da Biologia, da Física e da Matemática necessários para a compreensão dos fenômenos; 4) bem como, a mobilização dos mesmos para estudar os fenômenos e seus impactos nos desdobramentos sociais do local (BORGES, FARIA e BRICK, 2017, p. 973).

A primeira atividade foi listar fenômenos que estivessem ligados ao contexto e território dos estudantes e associado a isso realizaram pesquisas em diferentes fontes sobre os territórios/fenômenos, com o intuito de aumentar o conhecimento sobre os itens selecionados. A partir da lista dos diferentes fenômenos, foi necessário criar critérios para definir quais desses fenômenos seriam efetivamente estudados no componente. Assim o coletivo definiu os seguintes critérios para escolha dos fenômenos: "[...] situado na região/localidade de realização TC [Tempo Comunidade]; [...] relacionado com a dinâmica da vida social e familiar; [...] relacionado aos 
princípios do Movimento da Educação do Campo" (BORGES, FARIA e BRICK, 2017, p. 977). Definidos os fenômenos, foram elaborados diagramas (regressão linear, malha conceitual e mapa de referências) a fim de evidenciar as relações e desdobramentos dos fenômenos com conceitos científicos das Ciências da Natureza e da Matemática. Nessa prática pedagógica destaca-se a pesquisa, a relação com a vivência e território dos estudantes e as possibilidades de relações multi e interdisciplinares.

Borges Junior, Ferreira e Aranha (2018) trabalharam com a produção de tinta de terra com licenciandos de Educação do Campo da Universidade Federal do Maranhão no componente de história da química. A produção de tinta de terra objetivou trabalhar com a química dos pigmentos, por meio da perspectiva da Ciência, Tecnologia, Sociedade e Ambiente (CTSA). A CTSA é uma forma de promover a tomada de decisões na sociedade, despertando o interesse na aprendizagem, por favorecer a utilização de materiais do cotidiano dos estudantes. "A contextualização da temática química dos pigmentos se deu por meio da produção da tinta de terra e dos debates sobre contaminação por chumbo, educação em saúde, educação ambiental e sustentabilidade" (BORGES JUNIOR, FERREIRA e ARANHA, 2018, p. 601). Após os estudantes conhecerem o material necessário a ser utilizado na prática e realizarem discussões teóricas, colocaram a "mão na massa": produção da tinta de terra, pintura e exposição de cerâmicas. "Além da redução dos gastos financeiros [...] esta tecnologia elimina os impactos à saúde humana e minimiza os impactos ao meio ambiente, ao considerar que nenhum dos ingredientes necessários apresenta toxicidade" (BORGES JUNIOR, FERREIRA e ARANHA, 2018, p. 605). Essa prática pedagógica possibilitou articular questões referentes a sustentabilidade social, econômica e ambiental; conhecer tecnologias de baixo custo e ambientalmente saldáveis e; resgatar, contribuir e valorizar os fatos e experiências do cotidiano, possibilitando o aprender de maneira significativa.

Fonseca, Duso e Hoffmann (2017) utilizaram a abordagem das Controvérsias Sociocientíficas (CSC) no componente "Construindo Conhecimento de Biologia no Ensino Fundamental" para discutir a temática dos agrotóxicos e saúde com licenciandos no curso de Educação do Campo - Ciências da Natureza, da Universidade Federal do Pampa em Dom Pedrito no Rio Grande do Sul. Essa abordagem objetivou evidenciar que tomadas de decisões estão vinculadas a questões éticas, políticas sobre a ciências, tecnologia, sociedade e ambiente; e "conhecer os níveis de organização biológica dos 
seres vivos, contextualizando-os às especificidades ligadas à realidade e problemáticas do campo" (FONSECA, DUSO e HOFFMANN, 2017, p. 886). De acordo com os autores (2017, p. 892) essa prática: “[...] pode motivar os estudantes a expressar suas opiniões, saber argumentar e tomar decisões bem fundamentadas no que diz respeito ao desenvolvimento científico e tecnológico e suas implicações para a sociedade”.

Köhler et al. (2018) trabalharam com o projeto "troca de saberes sobre botânica camponesa" com um grupo de mulheres e a Incubadora Tecnológica de Cooperativas Populares (ITCP) no Assentamento Filhos de Sepé no Rio Grande do Sul. O projeto teve por objetivo buscar caminhos para uma construção de diversos saberes relacionando a natureza, produção agroecológica e vida camponesa. Foram realizados 12 encontros em diferentes locais do assentamento, a partir de reuniões que ocorreram com o grupo de mulheres e a equipe da ITCP, nos quais foram planejadas ações oriundas das demandas para as quais o grupo buscava apoio. Alguns exemplos de demandas se referem a: como evitar os danos das formigas à horta, como aumentar a produção, como reconhecer e manter um solo fértil, como armazenar sementes, dentre outras. Os encontros se dividiram em três momentos: teórico-expositivo, teórico-prático e reflexivo-avaliativo, sendo que no primeiro foram apresentados os assuntos de forma oral, roda de conversas entre outros; já no segundo foram feitas atividades práticas envolvendo a "mão na massa"; no terceiro se fez refletir sobre as experiências vividas no processo todo, através de conversas e discussões. Como resultado de cada encontro, foram sendo construídos de maneira coletiva, saberes necessários a resolução das demandas. Segundo os autores "as vivências do projeto 'Trocas de Saberes Sobre Botânica Camponesa' representaram importantes acontecimentos para os sujeitos envolvidos, agregando em suas trajetórias profissionais e pessoais a rica experiência de viver seus sonhos de desenvolvimento" (KÖHLER et al. 2018, p. 779).

Barbosa (2018) inspirou-se na pedagogia freiriana, para trabalhar com física a partir de uma abordagem dialógica e problematizadora, com licenciandos do curso de Educação do Campo Ciências da Natureza da Universidade Federal do Pará. Assim deuse espaço aos estudantes para que pudessem se pronunciar e apontar temas ou questões que tivessem interesse ou curiosidade. A partir de algumas problematizações feita aos estudantes, os mesmos fizeram alguns questionamentos onde apontaram coisas de interesses e curiosidades pessoais, como por exemplo: falta de água e de energia 
elétrica, velocidade de embarcação, pressão do ar em terrário... A partir desses temas coube ao professor mostrar suas relações com os conteúdos de física. De acordo com o autor "é preciso escapar desde círculo vicioso do conteúdo como fim, para o conteúdo como um meio para compreender, agir e transformar a realidade" (BARBOSA, 2018, p. 200). Essa prática pedagógica possibilitou uma participação maior dos estudantes pois os processos da física tinham relação com assuntos e questões de seu cotidiano.

Formigosa et al. (2017) trabalharam com o júri simulado e a tempestade cerebral com licenciandos de Educação do Campo da Universidade Federal do Pará no componente de física. O júri simulado consiste em simular um julgamento sobre alguma situação de conflito, na qual a turma de estudantes é organizada de acordo com as diferentes representações de um júri. No caso desenvolvido por Formigosa et al. (2017) o conflito escolhido foi a implantação de uma hidrelétrica na região e os estudantes tiveram que se posicionar contra e a favor. Para criarem argumentos tiveram que realizar pesquisa e buscar informações, o que foi feito em diferentes fontes: vídeos, fotografias, reportagens e pesquisas na internet. De acordo com os autores essa prática de ensino permite que sejam desenvolvidos argumentos e debates de temas e conteúdos; e possibilita o trabalho coletivo e em pequenos grupos; "os alunos argumentaram que a mesma lhes deixou "livres" para desenvolverem seus argumentos de acordo com a compreensão daquilo que pesquisaram" (FORMIGOSA et al., 2017, p. 913). A tempestade cerebral permitiu aos estudantes apresentarem diferentes ideias a partir de um determinado tema. Utilizaram como base a implementação da Usina Hidrelétrica de Belo Monte na região. Os estudantes foram divididos em grupos onde cada um teve que escrever uma palavra que remetesse a palavra: "eletricidade". A partir desses conceitos os estudantes escreveram palavras como: elétrica, tensão, força, energia, luz, tecnologia, água, etc. De acordo com os autores essa prática permitiu aos estudantes a possibilidades de trazer diferentes temas a serem discutidos e vivenciados por eles.

Crepalde, Klepka e Pinto (2017) trabalharam com a perspectiva intercultural, a qual pode ser entendida enquanto metodologia de articulação dos saberes científicos e os saberes populares. Na prática pedagógica desenvolvida na disciplina de "Introdução a Física" do curso de Licenciatura em Educação do Campo da Universidade Federal do Triângulo Mineiro o tema escolhido para o trabalho foi a lua. Nesse artigo além de compartilharem a prática pedagógica desenvolvida, também apresentam os resultados 
da pesquisa realizada por meio de revisão bibliográfica na Revista Brasileira de Agroecologia. A partir dessa revisão os autores mencionam práticas interculturais a respeito dos conhecimentos sobre a lua: uma prática foi à elaboração de material paradidático falando sobre a questão alimentação e a relação com a lua; a outra montou um calendário indicando em cada fase da lua quais os processos a serem feitos e seus benefícios; outra realizou trabalho etnográfico relacionando o sistema da lua para um entendimento do equilíbrio, harmonia e reciprocidade no que se refere ao modo e momento certo de plantio. A prática efetivada pelos autores consistiu em propor que os acadêmicos realizassem uma pesquisa com trabalhadores do campo para saber quais seus conhecimentos a respeito das fases da lua e das atividades no campo: agricultura e pesca. "[...] a Lua, enquanto artefato cultural (da ciência, da arte, da tradição, da literatura, etc.), tem inquestionável influência no ambiente e vida terrestre do ponto de vista de qualquer conhecimento" (CREPALDE, KLEPKA e PINTO, 2017, p. 848). A partir dos conhecimentos dos sujeitos do campo, desses saberes populares, foram tecidos diálogos com os saberes científicos.

Tais práticas evidenciam que o professor deve dar o espaço para os estudantes exporem seus conhecimentos e adaptar os conteúdos de acordo com o contexto e cotidiano dos mesmos. Dessa maneira o professor pode fazer a diferença buscando construir alternativas que permitam a construção de conhecimento significativo e também envolvendo a diversidade de estudantes e suas dificuldades de aprendizagem. Por meio de práticas como essas os estudantes aprendem de forma contextualizada e são ativos na sua aprendizagem.

No que se refere ao Ensino de Ciências as pesquisas selecionadas revelam a importância de ultrapassarmos a visão da aprendizagem como apropriação mecânica informacional, de maneira a possibilitar a participação e interação ativa do aprendiz em relação aos novos conhecimentos e conceitos. Laburu, Arruda e Nardi (2003, p.248) colaboram para essa compreensão quando caracterizam o processo de aprendizagem como “[...] complexo, mutável no tempo, que envolve múltiplos saberes e está longe de ser trivial" e a partir dessa caracterização propõem o pluralismo metodológico no Ensino de Ciências, o qual pluralismo está expresso na diversidade de práticas pedagógicas identificadas nessa investigação. 
Com relação a Educação do Campo, as práticas selecionadas e analisadas nessa investigação corroboram com abordagens propostas por Caldart (2004) de que a educação dos povos do campo contemple: a valorização da agricultura familiar e da agroecologia popular; o vínculo com as lutas sociais; o debate sobre o modo de vida no campo como digno, viável e sustentável; a discussão sobre os direitos a educação, identidade, cultura, história e território; e a proposição de um projeto de campo que contemple as especificidades e saberes do campo.

Rosa e Robaina (2020, p. 172) ao desenvolverem pesquisa acerca de publicações que abordavam a Educação e o Ensino de Ciências entre 2013 e 2019, corroboram com a compreensão das articulações dessas duas áreas quando afirmam que:

Quando se cruzam os unitermos educação do campo e educação em ciências nota-se uma afinidade nesses campos, onde o princípio educativo parte do mesmo objetivo, educar pelo entorno, buscando conteúdos que sejam significativos e façam sentido para os educandos, embasados pela necessidade de uma comunidade escolar e aproveitando os saberes populares dos envolvidos. Ambos os unitermos ressaltam a necessidade de se buscar o conhecimento a partir da realidade em que se está inserido, buscando a aprendizagem através variados recursos didáticos e não somente o aprender pelo livro didático.

\section{CONSIDERAÇÕES FINAIS}

Os resultados da investigação apresentada nesse artigo mostram que a articulação da Educação do Campo com o Ensino de Ciências pode ser realizada por meio de práticas pedagógicas que envolvem: softwares educacionais; modelagem matemática; jogos matemáticos; fenômenos como mediadores dos conhecimentos; Ciência, Tecnologia, Sociedade e Ambiente (CTSA); Ciência, Tecnologia e Sociedade (CTS); temas geradores; júri simulado; tempestade cerebral e abordagem intercultural. Tais práticas possuem como pilares: a atuação e ação direta do estudante no processo de aprender; a relação saberes populares e conhecimento científico; a valorização dos conhecimentos prévios e do contexto local.

É possível observar que existem mais pesquisas sobre as práticas pedagógicas no ensino superior, o que por um lado denota a falta publicação de experiências no ensino médio e fundamental mas por outro lado demonstra que a formação de professores na Educação do Campo vem buscando diversificar as práticas pedagógicas no Ensino de 
Ciências. Com isso emerge a possibilidade de que essas práticas cheguem a outros níveis de ensino com a atuação desses professores que estão recentemente se formando e se inserindo nas escolas do campo. Por meio das publicações analisadas ainda que não tenha aparecido repetição de nenhuma prática, observamos que as mesmas se aproximam e que essa diversidade é interessante para nos dar um leque de opções que podem ser adaptadas de acordo com disciplina, nível de ensino e contextos locais.

\section{REFERÊNCIAS}

BARBOSA, R. O Ensino da Física na Educação do Campo: descolonizadora, instrumentalizadora e participativa. Revista Brasileira De Educação Do Campo, 3(1), 177-203. 2018. Disponível em: https://doi.org/10.20873/uft.2525-4863.2018v3n1p177. Acesso em: 26 mar 2019.

BECKER, F. Modelos Pedagógicos e Modelos Epistemológicos. In: KARKOTLI, G. (Org). Metodologia: construção de uma proposta científica. 2008. Curitiba: Camões. p. $45-56$.

BORGES JÚNIOR, M., FERREIRA, M., \& ARANHA, C. Oficina de tinta de terra: contextualizando pigmentos na disciplina de História da Química na LEdoC/UFMA.

Revista Brasileira De Educação Do Campo, 3(2), 596-615. 2018. Disponível em: https://doi.org/10.20873/uft.2525-4863.2018v3n2p596. Acesso em: 21 mar 2019.

BORGES, M., FARIA, J., \& BRICK, E. Fenômenos como mediadores do processo educativo em Ciências da Natureza e Matemática na Educação do Campo. Revista Brasileira De Educação Do Campo, 2(3), 965-990. 2017. Disponível em:

https://doi.org/10.20873/uft.2525-4863.2017v2n3p965. Acesso em: 21 mar 2019.

CALDART, R. Elementos para Construção do Projeto Político e Pedagógico da Educação do Campo. In: Contribuições para a Construção de um Projeto de Educação do Campo. MOLINA, M. C. e AZEVEDO DE JESUS, S. M. S. (Org.). 2004. Brasília, DF: Articulação Nacional "Por Uma Educação do Campo. p.10-31.

CREPALDE, R., KLEPKA, V., \& PINTO, T. Interculturalidade e conhecimento tradicional sobre a Lua na formação de professores no/do campo. Revista Brasileira De 
Educação Do Campo, 2(3), 836-860. 2017. Disponível em:

https://doi.org/10.20873/uft.2525-4863.2017v2n3p836. Acesso em: 18 mar 2019.

FERREIRA DE JESUS, E. L., \& SOUZA, R. Formação de professores quilombolas e o Programa Etnomatemática: repensando processos de ensino da Matemática. Revista Brasileira De Educação Do Campo, 3(3), 1064-1083. 2018. Disponível em: https://doi.org/10.20873/uft.2525-4863.2018v3n3p1064. Acesso em: 28 mar 2019. FONSECA, E. M. da; DUSO, L., \& HOFFMANN, M. B. Discutindo a temática agrotóxicos: uma abordagem por meio das controvérsias sociocientíficas. Revista Brasileira De Educação Do Campo, 2(3), 881-898. 2017. Disponível em: https://doi.org/10.20873/uft.2525-4863.2017v2n3p881. Acesso em: 29 mar 2019. FORMIGOSA, M.; QUARTIERI, M., DEL PINO, J., \& MARCHI, M. Júri simulado e tempestade cerebral: entendendo a implantação da Usina Hidrelétrica de Belo Monte. Revista Brasileira De Educação Do Campo, 2(3), 899-920. 2017. Disponível em: https://doi.org/10.20873/uft.2525-4863.2017v2n3p899. Acesso em: 21 fev 2019.

FRANCO, M. A. S. Práticas pedagógicas de acolhimento e inclusão: a perspectiva da pedagogia crítica. Revista on line de Política e Gestão Educacional. Araraquara, 21, (2), 964-978. 2017. Disponível em:

http://dx.doi.org/10.22633/rpge.v21.n.esp2.2017.10370. Acesso em: 05 mar 2019. KÖHLER, M., SANTOS, E., GIARETTA, C., GOMES, G., \& PINHEIRO, S. O educar-se no campo: caneta, enxada e botânica camponesa. Revista Brasileira De Educação Do Campo, 3(3), 763-783. 2018. Disponível em: https://doi.org/10.20873/uft.2525-4863.2018v3n3p763. Acesso em: 08 mar 2019. KUHN, A. Ensino Médio Técnico em Agroecologia e resistência no campo: o caso da Escola 25 de Maio, Fraiburgo (SC). Revista Brasileira De Educação Do Campo, 1(1), 107-127. 2016. Disponível em: https://doi.org/10.20873/uft.2525-4863.2016v1n1p107. Acesso em: 08 mar 2019.

LABURU, C. E., ARRUDA, S. de M., \& NARDI, R. Pluralismo metodológico no ensino de ciências. Ciência \& Educação (Bauru), Bauru, 9, (2), 247-260. 2003.

Disponível em: http://dx.doi.org/10.1590/S1516-73132003000200007. Acesso em: 14 maio 2019. 
LIMA, T. C. S. de, \& MIOTO, R. C. T. Procedimentos metodológicos na construção do conhecimento científico: a pesquisa bibliográfica. Rev. katálysis, Florianópolis, 10, n. spe, 37-45. 2007. Disponível em: http://dx.doi.org/10.1590/S141449802007000300004. Acesso em: 03 out. 2018.

MINAYO, M. C. de S. Análise qualitativa: teoria, passos e fidedignidade. Ciência \& Saúde Coletiva, Rio de Janeiro, 17, (3). 621-626. 2012. Disponível em:

http://dx.doi.org/10.1590/S1413-81232012000300007. Acesso em 18 ago. 2018.

MOLINA, M. C. Expansão das licenciaturas em Educação do Campo: desafios e potencialidades. Educar em Revista. Curitiba, 2015, n.55, 145-166. Disponível em: https://doi.org/10.1590/0104-4060.39849. Acesso em: 05 ago 2019.

NAHIRNE, A., \& STRIEDER, D. Escola do campo e a prática social de ensino da matemática na concepção da comunidade escolar. Revista Brasileira De Educação Do Campo, 3(2), 496-518. 2018. Disponível em: https://doi.org/10.20873/uft.25254863.2018v3n2p496-2. Acesso em: 18 mar 2019.

ROSA, S. S. da; ROBAINA, J. O Ensino de Ciências nas Escolas do Campo a partir da análise da produção acadêmica. Revista Insignare Scientia - RIS, v. 3, n. 2, p. 156175, 24 ago. 2020. Disponível em: https://doi.org/10.36661/2595-4520.2020v3i2.11161. Acesso em: 13 out 2020.

SANTOS, S., \& LEÃO, M. Uso de objetos educacionais digitais para ensinar sistemas do corpo humano em uma escola do campo. Revista Brasileira De Educação Do Campo, 2(3), 861-880. 2017. Disponível em: https://doi.org/10.20873/uft.25254863.2017v2n3p861. Acesso em: 24 fev 2019.

VASCONCELOS, C., PRAIA, J. F., \& ALMEIDA, L. S. Teorias de aprendizagem e o ensino/aprendizagem das ciências: da instrução à aprendizagem. Psicologia Escolar e Educacional, Campinas, 7, (1), 11-19. 2003. Disponível em: http://dx.doi.org/10.1590/S1413-85572003000100002. Acesso em 22 ago 2018. 